\title{
Healthy society as one of the main directions of the strategy for the development of sport in russia until 2030
}

\author{
Svetlana Pyankova*, and Dmitriy Arkalov \\ Ural State University of Economics, Yekaterinburg, Russia
}

\begin{abstract}
The article examines the Strategy for the development of physical culture and sports in the Russian Federation for the period up to 2030 from the standpoint of assessing the target indicator "The share of citizens who systematically involve in physical culture and sports (in the total number of citizens who do not have contraindications and restrictions for physical culture and sports)". Comparison with a similar indicator of the Strategy for the development of physical culture and sports in the Russian Federation for the period up to 2020 shows a positive trend, although the new Strategy states that statistical data differ within $15 \%$. The work says that mass sport is the most attractive form of a healthy lifestyle in comparison with other areas in this area. The importance of resource provision, organization of feedback from the population and the use of the obtained data in the implementation of state policy in this direction are noted. The authors propose the use of methods that will make it possible to better plan tactical actions to achieve all the target indicators of the Strategy for the Development of Physical Culture and Sports in the Russian Federation for the period up to 2030 .
\end{abstract}

\section{Introduction}

The healthy state of the country's population is one of the components, but not exhaustive properties of society and the state as a whole. Citizens' health forms the basis of human capital and opportunities for economic stability, development and growth. The creation of conditions for a healthy lifestyle and the promotion of well-being should be one of the priority tasks of the state internal policy. Otherwise, significant economic losses may be incurred [1]. By order of the Government of the Russian Federation dated November 24, 2020 No. 3081-r, the Strategy for the development of physical culture and sports in the Russian Federation for the period up to 2030 [2] (hereinafter referred to as Strategy 2030) was approved. The basis of the state's mission is made up of directions covering different aspects of the sports sphere. It is possible to single out a vector aimed at improving the health of the population: the formation of a culture and values of a healthy lifestyle as the basis for sustainable development of society and the quality of life of the population. The vector of the general development of the sports sphere is creating the necessary conditions

\footnotetext{
*Corresponding author: silen_06@list.ru
} 
for the progressive development of the sphere of physical culture and sports. The vector aimed at attracting private investment is increasing the economic attractiveness and efficiency of the functioning of the sphere of physical culture and sports. In the 2030 strategy, a particular attention is paid to attracting the business community, which was not in the Strategy for the development of physical culture and sports in the Russian Federation for the period until 2020, approved by the order of the Government of the Russian Federation dated August 7, 2009 No. 1101-r [3]. The need for this direction was noted by N.V. Parshikova. and others [4]. As well as the development of elite sports and Olympic sports: ensuring the transparency and honesty of the competitive process; strengthening international cooperation and increasing the authority of Russia in the international sports arena.

In terms of building a healthy society, the following priority direction of the Strategy has been formed: improving health and well-being, as well as increasing the standard of living of the population. According to the authors, in this direction, it is necessary to improve the methods that ensure health, well-being and living standards, and not the conditions themselves.

\section{Materials and methods}

In practice, there are several main areas of sports: mass sports, professional sports, highperformance sports. These concepts are also enshrined in federal legislation [5]. For most of the population, the most suitable direction is mass sports, which is aimed at physical education and physical development of citizens. The concept of "mass sports" includes the entire population from 3 to 79 years old or more, with the exception of citizens involved in elite sports and professional sports. This statement is confirmed by the statistics of the Ministry of Sports of Russia, according to which in 2020 the total number of people involved in physical culture and sports amounted to 62 million people, of which only about 4,5 million people $(7,2 \%)$ are in sports training [6a]. Some researchers believe that at the current stage the value of mass sports is increasing as one of the most promising areas for overcoming the social and spiritual crisis of modern society [7]. In Figure 1, the authors provide a diagram of the interaction of various sport trends from the perspective of set theory.

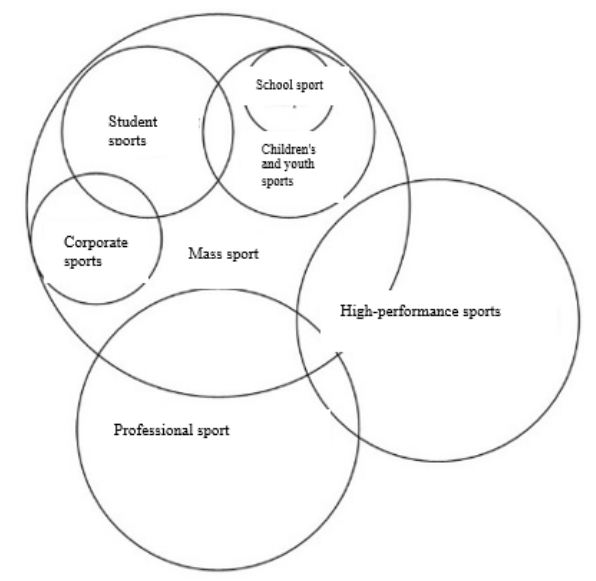

Fig. 1. Actual trends in sports: mass sports, school sports, children's and youth sports, student sports, corporate sports, high-performance sports, professional sports. 
Figure 1 shows that mass sports is the most general concept that includes school sports, which in turn is part of children's and youth sports and is actually the initial basis for the further construction of the sports system. When they reach a certain age, children move from youth sports to student sports, which come into contact with corporate sports. A special place is occupied by high-performance sports and professional sports, in which the most talented and promising athletes take part. It is worth noting that mass sports include all amateur starts, in which the population takes part, involved individually, as well as the elderly people.

As of the end of 2020, the most widespread age categories of citizens involved in sports in Russia were children from 3 to 15 years old and adults from 30 to 59 years old [6b]. Figure 2 shows statistical data on the age ratio.
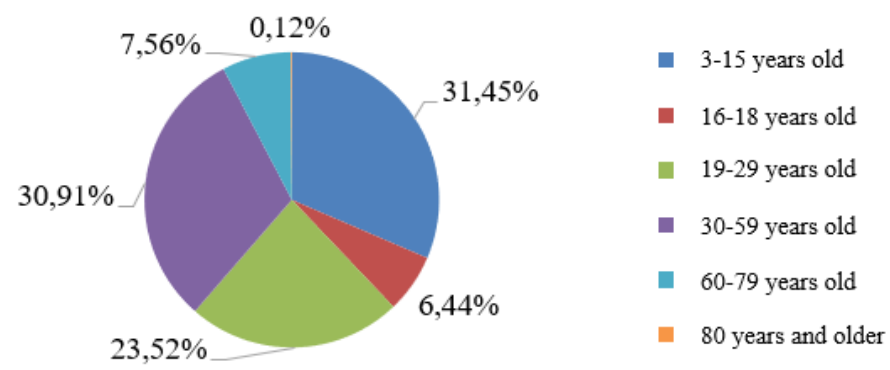

Fig. 2. Age ratio of citizens involved in sports in Russia in 2020: 3-15 years old, 16-18 years old, 1929 years old, 30-59 years old, 60-79 years old, 80 years and older.

Figure 2 shows that the smallest age category of citizens involved in physical culture and sports is the category of 80 years and older. Its share is $0,12 \%$. Also small are the categories of $16-18$ years and $60-79$ years $(6,44 \%$ and $7,56 \%$, respectively). The age of $16-$ 18 years coincides with the age of admission of students to higher education institutions. However, the next category of 19-29 years coincides with students and working youth, and the number of students increases to $23,52 \%$. The category of $60-79$ years shows a natural decline in physical activity, given that according to the Federal State Statistics Service of Russia, the average life expectancy for 2019 was 73,34 years [8].

In the Strategy 2020, the target indicator "The share of citizens of the Russian Federation systematically involved in physical culture and sports in the total population, \%" had a step of five years. Starting from the base value of $15,9 \%$, by 2015 it was supposed to be $30 \%$, and by $2020-40 \%$, i.e. this indicator was supposed to increase by 2,52 times, taking into account the change in the population. The actual value was $43 \%$, which served as the base value for the Strategy 2030 for this indicator. Table 1 shows data on sports financing and the share of mass sports financing according to the reporting information in the Strategy 2030, as well as calculated data according to statistical reports (columns 4-6).

Table 1. Strategy 2020 indicators

\begin{tabular}{|c|c|c|c|c|c|}
\hline Year & $\begin{array}{c}\text { Amount of } \\
\text { funding for } \\
\text { the sports } \\
\text { sector, } \\
\text { million } \\
\text { rubles. }\end{array}$ & $\begin{array}{c}\text { Share of } \\
\text { funding for } \\
\text { mass sports, } \%\end{array}$ & $\begin{array}{c}\text { Share of } \\
\text { funding for } \\
\text { mass sports, } \\
\text { million rubles. }\end{array}$ & $\begin{array}{c}\text { Number of } \\
\text { people } \\
\text { involved in } \\
\text { mass sports, } \\
\text { million people. } \\
{[9,10]}\end{array}$ & $\begin{array}{c}\text { Average } \\
\text { amount of } \\
\text { funding per 1 } \\
\text { person, rubles }\end{array}$ \\
\hline 1 & 2 & 3 & 4 & 5 & 6 \\
\hline 2015 & 254900,00 & 38,30 & 97626,70 & 39,20 & 2490,61 \\
\hline 2019 & 375400,00 & 48,20 & 180942,80 & 54,14 & 3342,37 \\
\hline
\end{tabular}


Table 1 shows that in 2015, 97,63 billion rubles were allocated for the formation of a healthy lifestyle within the framework of mass sports, and in 2019 this figure was already 108,94 billion rubles, i.e. funding increased by 1,85 times. The number of people involved in sports increased by 1,38 times, and the average financial costs per 1 person increased by 1,34 times.

Entering into the calculation of state budget investments the inflation rate from December 2015 to December 2019, which amounted to 16,97\% [11], the purchasing power of money in 2019, directed to mass sports, will be 154,69 billion rubles compared to 2015 , and the cost of 1 person will amount to 2857,46 rubles, i.e. financing relative to purchasing power increased by 1,58 times and 1,15 times, respectively.

According to the target indicator «The share of citizens systematically involved in physical culture and sports (in the total number of citizens who do not have contraindications and restrictions for physical culture and sports)" of the Strategy 2030, the percentage values during its implementation should be according to Table 2 . We will also calculate the basic and chain growth coefficients.

Table 2. Projected dynamics of the target indicator changes

\begin{tabular}{|c|c|c|c|}
\hline \multirow{2}{*}{ Period } & \multirow{2}{*}{$\begin{array}{c}\text { Indicator } \\
\text { value }\end{array}$} & \multicolumn{2}{|c|}{ Growth rate } \\
\cline { 3 - 4 } & 2 & chain & basic \\
\hline 1 & 2 & 3 & 4 \\
\hline 2020 & $43,0 \%$ & & \\
\hline 2021 & $45,2 \%$ & 1,05 & 1,05 \\
\hline 2022 & $48,0 \%$ & 1,06 & 1,12 \\
\hline 2023 & $51,5 \%$ & 1,07 & 1,20 \\
\hline 2024 & $55,0 \%$ & 1,07 & 1,28 \\
\hline 2025 & $57,0 \%$ & 1,04 & 1,33 \\
\hline 2026 & $59,0 \%$ & 1,04 & 1,37 \\
\hline 2027 & $61,5 \%$ & 1,04 & 1,43 \\
\hline 2028 & $64,0 \%$ & 1,04 & 1,49 \\
\hline 2029 & $67,0 \%$ & 1,05 & 1,56 \\
\hline 2030 & $70,0 \%$ & 1,04 & 1,63 \\
\hline
\end{tabular}

In Table 2, the chain growth rate is calculated as the ratio of the target value of the next period to the previous one. The baseline growth rate is calculated as the ratio of the target value of each subsequent period to the initial one (2020).

Comparing the data for the target indicator of the Strategy 2020 and the Strategy 2030 for the baseline growth rate, which were 2,25 and 1,63, respectively, we state that the rate has decreased. But this does not reduce the scale of this target by 2030 .

\section{Results and discussions}

One of the risks of achieving this indicator and involving citizens in sports is a change in the structure of income of citizens and a drop in demand for relevant services, which is noted in the Strategy 2030. According to research conducted by scientists of the Plekhanov Russian University of Economics, the share of public spending on sports and recreation services is insignificant and is not in the first place [12]. 
On the other hand, taking into account the transformation in terms of the orientation towards market relations [13], sports services, despite the numerous state projects in the field of mass sports (Russian cross-country skiing, National cross-country skiing, rural games, amateur games, etc.), are also in demand in the commercial sector. The number of citizens engaged in paid sports is 19827,2 million people, which is $20,9 \%$ of the total number of people involved in sports [6c]. In recent years, interest in amateur sports has increased: various marathons, half-marathons, triathlon and cycling competitions. And there is also an active development of the club system [14]. These trends must necessarily be supported by the state. This is not only a social function to the population, but also support for private initiatives, which can reduce a small part of the budget charges. At the initiative stage, it is important to support and assist with administrative resources. When organizing systematic physical activity, it gives a total effect that has a positive effect on overall health [15].

Recently, the popularity of data obtained from the field of sports for studying the economic behavior of the population has been growing [16]. This, in turn, can be a working tool for adjusting the ways in which the goals are implemented in order to achieve the targets of the Strategy 2030. Setting up feedback directly with the recipients of sports services will create additional levels of control and help to understand the needs of the population in this sector [17]. Given that the Strategy 2030 has already been adopted and is undergoing the first stage of implementation, tactical actions will need to be adjusted by regulatory acts at each level of government. Taking into account modern innovative technologies, the specifics of the budgets of different regions and municipalities, and for a more "sensitive" understanding of the public demand for the type of sports services, their quantity and quality, it is necessary to use a "failure-project-target approach" [18].

When monitoring targets at reference points, in addition to fixing their actual achievement or the reasons for not achieving them, it is necessary to conduct an analysis based on the "cost-result" principle used in the concept of social return on investment (SROI), which will complement the existing theoretical provisions and adjust the applied calculation and analytical tools and algorithms [19].

\section{Conclusions}

An important factor in the implementation of all the targets and the Strategy 2030 as a system as a whole will be the resource provision necessary for the implementation of the final products, expressed, in many positions, in concrete measurable results. First of all, financial and personnel support. The quality and speed of interaction between different levels of government, implementers and recipients will largely determine the organization of the process for implementing the Strategy 2030.

\section{References}

1. A.S. Brutova, O. V. Obukhova, I.N. Bazarova, Medical technologies. Evaluation and Choice, 2(28), 44 (2017)

2. Order of the Government of the Russian Federation of November 24, 2020 No. 3081-r "On approval of the Strategy for the development of physical culture and sports in the Russian Federation for the period up to 2030".

3. Order of the Government of the Russian Federation dated August 7, 2009 No. 1101-r. "On approval of the Strategy for the development of physical culture and sports in the Russian Federation for the period up to 2020". 
4. N.V. Parshikova, S.I. Izaak, V.N. Malitz, Theory and practice of physical culture, 12, 3 (2017)

5. Federal Law "On Physical Culture and Sports in the Russian Federation" dated 04.12.2007 No. 329-FZ.

6. Consolidated report 1-FC for the Russian Federation for 2020, https://minsport.gov.ru/

7. I.E. Ponomarev, et al. State and municipal administration. Scientific notes., 1, 236 (2019)

8. Official website of the Federal State Statistics Service, https://rosstat.gov.ru/

9. Consolidated report 1-FC for the Russian Federation for 2015, https://minsport.gov.ru/

10. Consolidated report 1-FC for the Russian Federation for 2019, https://minsport.gov.ru/

11. Inflation in Russia, https://уровень-инфляции.рф

12. O.P. Pidyashova, T.E. Kravchenko, T.A. Tereshchenko, Bulletin of the Academy of Knowledge, 32(3), 209 (2019)

13. D.O. Chavkin, I.M. Kornilov, A.S. Fomina, Theory and practice of physical culture, 12, 6 (2018)

14. V.A. Lednev, Modern Competition, 14, 1(77), 106 (2020)

15. D.C. Nieman, L.M. Wentz, Journal of Sport and Health Science, 8(3), 201 (2019)

16. M.B. Eliab, A. Krumerc, E. Morgulevdba, Journal of Behavioral and Experimental Economics, 89 (2020)

17. A.S. Konychev, I.I. Frolova, Innovative Economy: Prospects for Development and Improvement, 6(16), 60 (2016)

18. S.G. Pyankova, O.T. Ergunova, V.K. Krastev, First conference on sustainable development: industrial future of territories (2020)

19. Litvin A.V., Kazakov A.N., L. Esipovich, Theory and practice of physical culture, 1, 40 (2017) 